\title{
INIBIÇÃO DO CRESCIMENTO IN VITRO DE FITOPATÓGENOS SOB DIFERENTES CONCENTRAÇÕES DE EXTRATOS DE PLANTAS MEDICINAIS
}

\author{
L.R. Venturoso*, L.M.A. Bacchi, W.L. Gavassoni, L.A. Conus, B.C.A. Pontim, F.R. Souza
}

Universidade Federal da Grande Dourados, Faculdade de Ciências Agrárias, Laboratório de Fitopatologia, CP 533, CEP 79804-970, Dourados, MS, Brasil. E-mail: luck_rv@hotmail.com

\section{RESUMO}

\begin{abstract}
Com o objetivo de avaliar in vitro o efeito de diferentes concentrações de extratos vegetais sobre o crescimento de Cercospora kikuchii, Fusarium solani, Colletotrichum sp. e Phomopsis sp., foram conduzidos quatro bioensaios experimentais, no Laboratório de Fitopatologia da Universidade Federal da Grande Dourados. Foi adotado o delineamento inteiramente casualizado em arranjo fatorial $3 \times 6$, com 8 repetições para cada bioensaio. Foram utilizados extratos aquosos de alho, canela e cravo-da-índia, nas concentrações de $0 ; 0,5 ; 1 ; 5 ; 10$ e 20\%. Para obtenção dos extratos foram coletadas $30 \mathrm{~g}$ do material vegetal e trituradas em $120 \mathrm{~mL}$ de água destilada. Os extratos foram filtrados em papel Wathman $n^{\circ} 1$ e incorporados ao meio BDA, de modo a obter as concentrações desejadas. Posteriormente, a solução foi vertida em placas de Petri, onde foram transferidos discos de micélio do patógeno, de 0,3 cm de diâmetro. Em seguida, as placas foram incubadas a $25^{\circ} \mathrm{C}$, com fotoperíodo de 12 horas. Foi analisado o crescimento micelial da colônia fúngica. Os resultados revelaram que o efeito do extrato aquoso de canela para todos os patógenos estudados, e do extrato de alho para F. solani, Colletotrichum sp. e Phomopsis sp. foi dependente das concentrações utilizadas, constatando-se maior atividade antifúngica com o aumento das concentrações. Verificou-se com o uso do extrato de cravo-da-índia maior eficácia no controle dos fitopatógenos testados, sendo observada supressão sobre o crescimento de Colletotrichum sp., Cercospora kikuchii, F. solani e de Phomopsis sp. a partir das concentrações de 7,4, 7,5, 8,9 e 7,0\%, respectivamente. O extrato aquoso de alho, na concentração de $9,7 \%$, apresentou efetivo controle apenas sobre C. kikuchii.
\end{abstract}

PALAVRAS-CHAVE: Controle alternativo, propriedades antifúngicas, extrato de plantas.

\section{ABSTRACT}

IN VITRO INHIBITION OF FUNGAL PLANT PATHOGENS BY DIFFERENT CONCENTRATIONS OF MEDICINAL PLANTS EXTRACTS. In order to evaluate the in vitro effect of different concentrations of plant extracts on the growth of Cercospora kikuchii, Fusarium solani, Colletotrichum sp. and Phomopsis sp., 4 bioassays experiments were conducted at the Plant Pathology Laboratory of the Federal University of Grande Dourados, Brazil. The experimental design was a completely randomized design in a $3 \times 6$ factorial arrangement, with 8 replicates for each bioassay. Aqueous extracts of garlic, cinnamon and clove were evaluated in concentrations of $0,0.5,1,5,10$ and $20 \%$. Extracts were obtained through maceration of $30 \mathrm{~g}$ of plant material in $120 \mathrm{~mL}$ of distilled water. The extracts were filtered in grade- 1 Whatman paper and incorporated into PDA medium to obtain the desired concentrations. Subsequently, the solution was poured into Petri dishes, and then $3 \mathrm{~mm}$-diameter-PDA plugs with pathogen mycelium were transferred to the center of the PDA + plant extract Petri dish. Plates were incubated at $25^{\circ} \mathrm{C}$ with a 12-h-day photoperiod. Fungal growth was performed daily by measuring the colony diameter. The results showed that the effect of aqueous extract of cinnamon for all pathogens studied, and garlic extract for F. solani, Colletotrichum sp. and Phomopsis sp., was dependent on the concentrations used, noting a higher antifungal activity with increased concentrations used. Clove extract presented the greatest effectiveness for the control of the plant pathogens tested, with observed suppression on the growth of Colletotrichum sp. C. kikuchii, F. solani and Phomopsis

*Este artigo é parte da dissertação de mestrado do primeiro autor apresentada a Universidade Federal da Grande Dourados, para obtenção do título em Mestre em Agronomia. 
sp. at the concentrations $7.4,7.5,8.9$ and $7.0 \%$, respectively. The aqueous extract of garlic at a concentration of $9.7 \%$ presented effective control only for C. kikuchii.

KEY WORDS: Alternative control, antifungal activity, plant extract.

\section{INTRODUÇÃO}

A prática da agricultura traz como consequência a ocorrência de doenças de plantas em níveis que exigem o seu controle. O método mais recomendado de controleéo uso da resistência genética (LYON et al., 1995). Porém, nem todas as plantas são resistentes aos patógenos, enem todo material resistenteé adaptado às diferentes regiões. Dessa forma, o uso de agrotóxicos no controle de doenças tem sido cada vez mais frequente na agricultura (MоTOYAMA et al., 2003). Esta prática de proteção de plantas contra fitopatógenos apresenta-se como uma alternativa bastante atraente pela sua simplicidade e resultados satisfatórios em curto prazo. Entretanto, os aspectos positivos desse sistema são suprimidos com o passar do tempo e uma sucessão de desvantagens pode ocorrer como o acúmulo de substâncias nocivas no solo e água, com consequente contaminação do ambiente e do próprio homem, a ocorrência de micro-organismos resistentes, e o desequilíbrio ambiental pela falta de seletividade dos produtos utilizados (TALAMINI; STADNIK, 2004).

Nesse enfoque, uma nova política agrícola através da agricultura alternativa tem sido desenvolvida, voltada à minimização desses impactos no ambiente e ao homem por meio do controle alternativo de doenças de plantas, o qual inclui o controle biológico, a indução de resistência em plantas (BETTIOL, 1991) e o uso de produtos alternativos ao controle químico, como extratos e óleos vegetais, seja por sua ação fungitóxica direta, ou indiretamente por meio da ativação de mecanismos de defesa nas culturas tratadas.

Uma espécie de planta largamente utilizada e estudada, com resultados promissores, éo alho (Allium sativum). A planta contém duas substâncias, aliinase e aliína, armazenadas separadamente e, quando suas membranas são rompidas, formam a alicina, responsável pela defesa da planta. Seus efeitos tóxicos inativam os micro-organismos (HEINZMANN, 2001). De acordo com RANASINGHE et al. (2002), o cravo-daíndia (Syzygium aromaticum) e a canela (Cinnamomum zeylanicum) também apresentam propriedades fungitóxicas. Os autores afirmam que o eugenol presente no cravo-da-índia pode ser o componente tóxico, tanto no extrato aquoso quanto no óleo essencial. Já a casca de canela tem, como principal constituinte antimicrobiano, o cinamaldeído.

Tem-se constatado com frequência a ocorrência de diferenças na inibição do desenvolvimento dos fitopatógenos frente às diferentes concentrações de extratos vegetais testados. De modo geral, verifica-se uma tendência de que quanto maior a sua concentração no meio de cultura, maior o efeito deste extrato no sentido de inibir o crescimento micelial dos fungos. Mоточама et al. (2003), em trabalhos com extratos cítricos, observaram inibição do crescimento micelial de Fusarium semitectum a partir da concentração de 100 ppm, entretanto, a máxima inibição foi verificada com a utilização da maior concentração, 5.000 ppm (48,18\%). BARROS et al. (1995), em experimentos com os fungos dos gêneros Curvularia e Alternaria, verificaram maior inibição do desenvolvimento das colônias fúngicas, com a utilização do extrato de alho na concentração de 10.000 ppm, quando comparado à concentração de 1.000 ppm.

Em outras ocasiões, não são detectados efeitos das concentrações dos extratos. Rodrigues et al. (2006), avaliando o potencial da planta Ocimum gratissimum no controle de Bipolaris sorokiniana, verificaram que tanto o extrato esterilizado por meio de filtração, como o autoclavado, nas concentrações de 5, 10, 15, 20 e $50 \%$ e 10, 15,20 e $50 \%$, respectivamente, proporcionaram semelhantes porcentagens de inibição do crescimento micelial do patógeno.

Tendo em vista a propriedade inibitória de extratos vegetais sobre o desenvolvimento de fungos fitopatogênicos, objetivou-se avaliar in vitro o efeito de diferentes concentrações dos extratos aquosos de alho, canela e cravo-da-índia sobre o crescimento de Cercosporakikuchii, Fusarium solani, Colletotrichum sp. e Phomopsis sp.

\section{MATERIAL E MÉTODOS}

Os bioensaios experimentais foram conduzidos no Laboratório de Fitopatologia da Universidade Federal da Grande Dourados (UFGD), no período de julho a novembro de 2008.

Foi adotado o delineamento experimental inteiramente casualizado, em arranjo fatorial $3 \times 6, \operatorname{com} 8$ repetições para cada bioensaio. Foram utilizados os extratos aquosos dealho (Allium sativum L., Liliaceae), canela (Cinnamomum zeylanicum Breym, Lauraceae) e cravo-da-índia [Syzygium aromaticum (L.) Merr. \& Perry, Myrtaceae], nas concentrações de $0 ; 0,5 ; 1 ; 5$; 10 e $20 \%$. Para realização de cada bioensaio foram utilizados os respectivos fungos: C. kikuchii, F. solani, Colletotrichum sp. e Phomopsis sp., fornecidos pela Embrapa Soja.

As plantas medicinais foram coletadas no Horto de Plantas Medicinais da UFGD e em produtores 
locais, no mês de julho. Os extratos aquosos foram obtidos por meio da coleta de $30 \mathrm{~g}$ do material vegetal natural, neste caso, bulbos de alho, casca de canela e botão floral de cravo-da-índia, e triturados em liquidificador com $120 \mathrm{~mL}$ de água destilada. Os extratos foram utilizados no mesmo dia de sua realização.

O material obtido após a trituração foi filtrado em papel Wathman $n^{\circ} 1$ e recolhido em Erlenmeyer devidamente identificado. O filtrado foi adicionado ao meio de cultura Batata-dextrose-ágar (BDA) fundente, de modo a se obter as diferentes concentrações dos extratos a serem avaliados.

O meio homogeneizado foi vertido em placas de Petri e, depois de sua solidificação, efetuou-se a repicagem de um disco micelial de $0,3 \mathrm{~cm}$ de diâmetro dos fitopatógenos, retirados de colônias puras com sete dias de idade, no centro da superfície do meio de cultura com os respectivos tratamentos. Posteriormente, as placas de Petri foram vedadas com filme plástico e incubadas em câmara BOD a uma temperatura de $25^{\circ} \mathrm{C}$, com fotoperíodo de 12 horas.

Para avaliação da eficácia dos tratamentos foi mensurado o crescimento micelial das colônias fúngicas no momento que elas atingiram $3 / 4$ da superfície do meio de cultura (Stangarlin et al., 1999). Para obtenção do crescimento micelial dos fitopatógenos estudados, as placas foram riscadas em sentido perpendicular, no intuito de mensurar o crescimento radial da colônia em dois eixos ortogonais, sendo posteriormente calculada uma média por placa.

Os dados obtidos foram transformados em $\sqrt{x+1}$, e submetidos à análise de variância com auxílio do programa SISVAR. Verificando-se interação significativa entre os fatores, procederam-se os necessários desdobramentos, sendo realizada, para os extratos vegetais, comparação entre as médias por meio do teste de Tukey a $5 \%$ de probabilidade, e para as concentrações análise de regressão.

\section{RESULTADOS E DISCUSSÃO}

Os resultados da análise de variância revelaram interação significativa entre os fatores, extratos vegetais $x$ concentrações, sendo observadas diferenças nocrescimento micelial dos fitopatógenos em virtude das concentrações de cada extrato utilizado.

Nota-se na Figura 1 que o extrato aquoso de cravo-da-índia apresentou redução no diâmetro da colônia de Colletotrichum sp. logo a partir da menor concentração. Por meio da equação, pode-se verificar a total supressão do crescimento micelial do fungo com a utilização de concentrações superiores a $7,4 \%$. Resultados semelhantes foram relatados por Rozwalka et al. (2008), que verificaram total inibição do crescimento de Glomerella cingulata e Colletotrichum gloeosporioides, com o uso do extrato aquoso de cravo-da-índia na concentração de $10 \%$. Os autores afirmaram ainda que, em experimento prévio, o extrato aquoso na concentração de $1 \%$ apresentou-se igualmente eficiente.

Oefeito no crescimento micelial de Colletotrichum sp., submetido ao meio de cultura com adição dos extratos aquosos de alho e canela apresentaram respostas semelhantes como aumento das concentrações utilizadas, verificando-se menor diâmetro da colônia fúngica nas maiores concentrações. Constata-se, no entanto, uma redução mais expressiva no crescimento do patógeno quando submetido ao tratamento com extrato de alho.

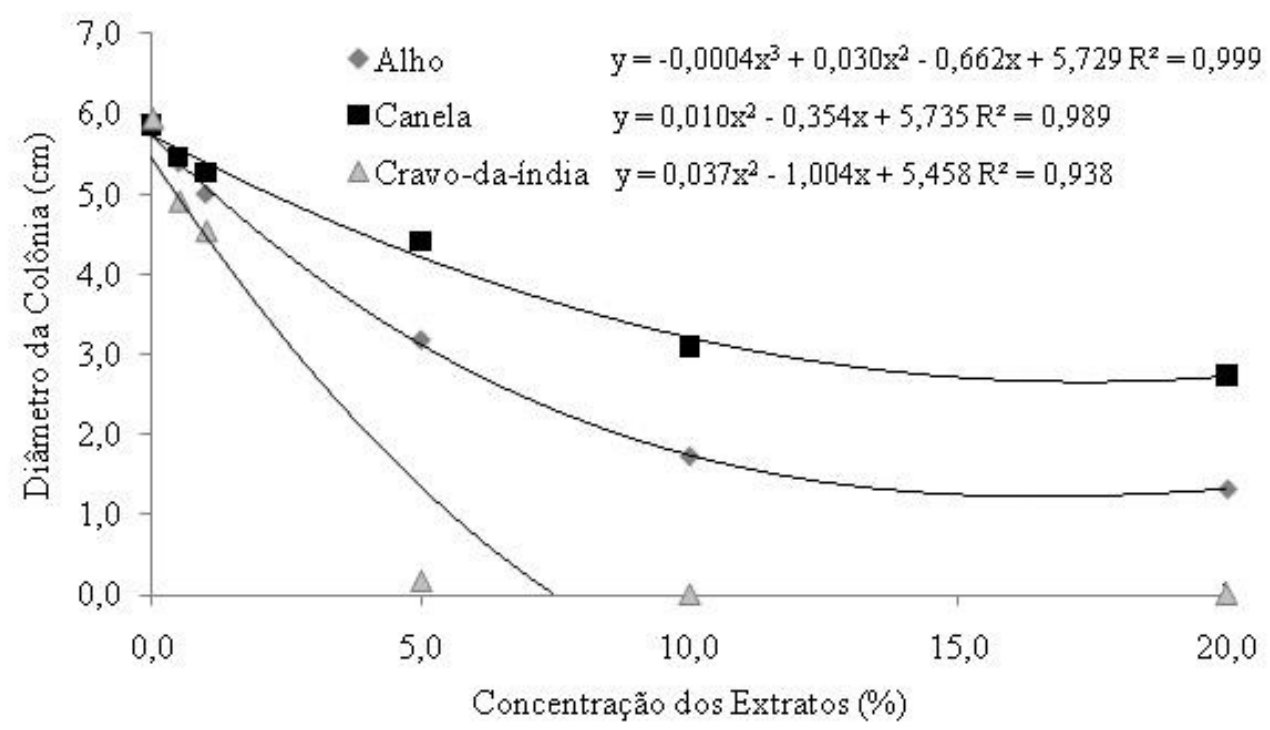

Fig. 1 - Crescimento micelial (cm) de Colletotrichum sp. sob influência de diferentes concentrações de extratos aquosos, Dourados, MS, 2008. 
RIBEIRO; BEDENDO (1999) verificaram que, dentre quatro extratos vegetais testados, aquele proveniente de alho resultou em efeitos mais drásticos sobre $C$. gloeosporioides, reduzindo em $67,6 \%$ o crescimento do patógeno em relação à testemunha. BIANCHI et al. (1997) verificaram inibições de $42 \%$ sobre o crescimento de Colletotrichum lindemuthianum na concentração de $10 \%$ desse extrato, valores menores que os encontrados neste estudo, porém, os autores observaram, por meio de microscopia eletrônica, colapso das hifas do patógeno quando tratadas com o extrato de alho evidenciando, assim, a ação fungitóxica do extrato.
Oextratoaquoso decanela promoveu uma redução linear sobre o diâmetro da colônia de C. kikuchii, com o aumento das concentrações utilizadas (Fig. 2). Os extratos aquosos de alho e cravo-da-índia apresentaram comportamento semelhante quantoà redução do crescimento micelial do patógeno. Ambos os extratos reduziram de forma mais efetiva o crescimento de $C$. kikuchii, em relação ao extrato proveniente da casca de canela. Por meio do modelo de regressão encontrado para os extratos, estima-se que concentrações superiores a 7,5\% para o extrato de cravo-da-índia e 9,7\% para o extrato de alho possibilitariam efetivo controle sobre o crescimento micelial do patógeno.

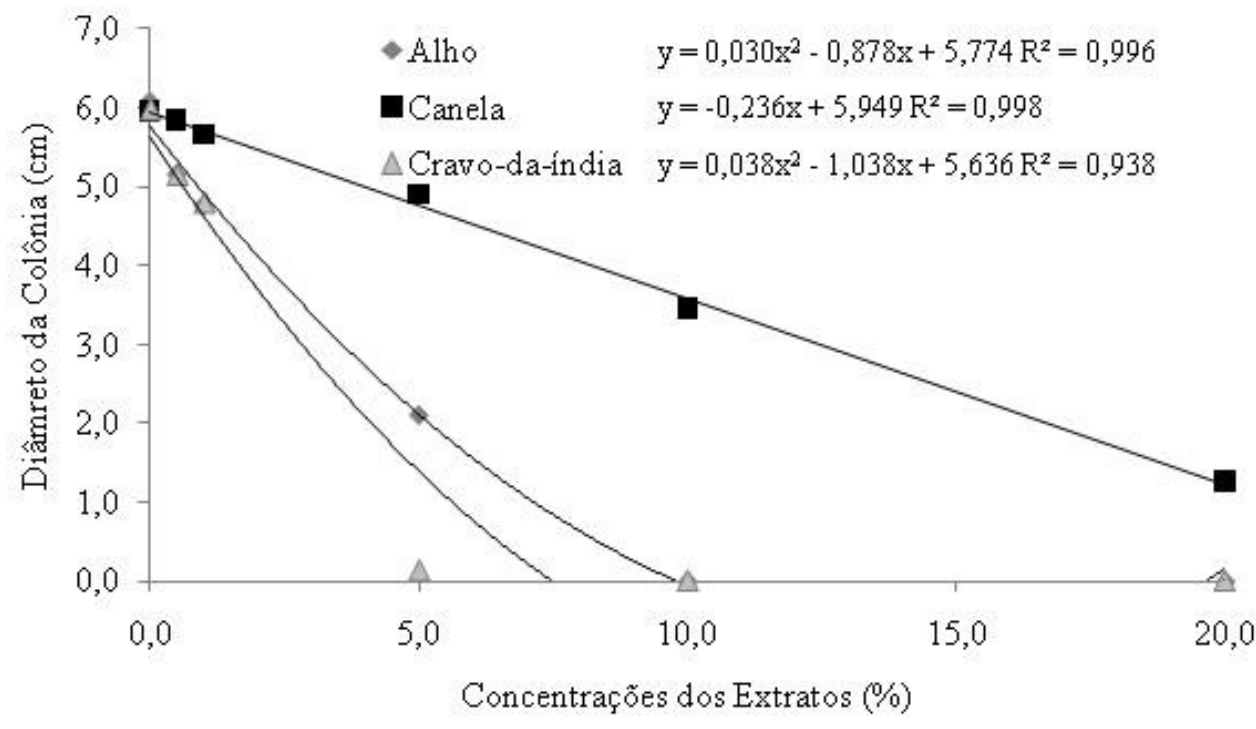

Fig. 2 - Crescimento micelial (cm) de Cercospora kikuchii sob influência de diferentes concentrações de extratos aquosos, Dourados, MS, 2008.

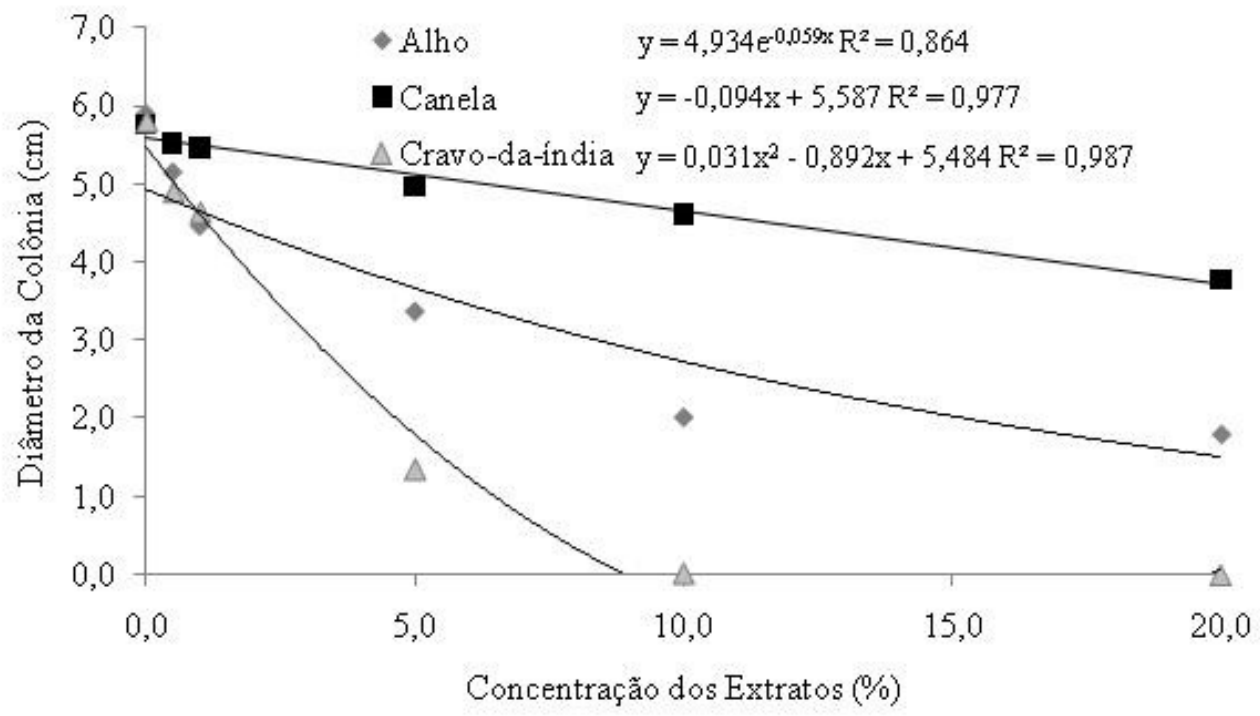

Fig. 3 - Crescimento micelial $(\mathrm{cm})$ de Fusarium solani sob influência de diferentes concentrações de extratos aquosos, Dourados, MS, 2008. 


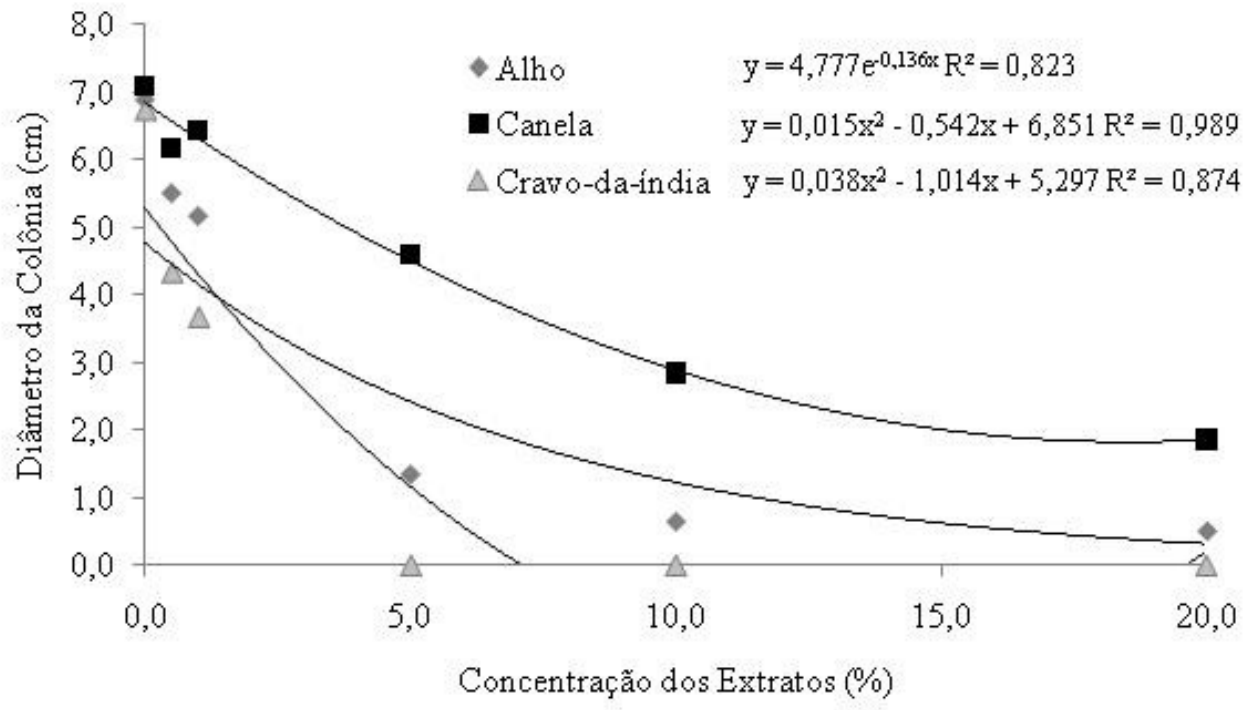

Fig. 4 - Crescimento micelial (cm) de Phomopsis sp. sob influência de diferentes concentrações de extratos aquosos, Dourados, MS, 2008.

Além da atividade antifúngica demonstrada pelos extratos aquosos, foram observadas alterações na coloração das colônias fúngicas, pois estas se apresentaram rosadas em meio BDA, e assumiram coloração branca com o aumento das concentrações dos extratos incorporados ao meio de cultura. Comportamento semelhante foi relatado por FRANZENER et al. (2003) que verificaram alterações morfológicas nas colônias de B. sorokiniana, sobretudo na cor, pois se apresentaram escuras, quase negras, em BDA, e assumiram coloração esbranquiçada com o aumento das concentrações do extrato aquoso de cânfora.

Verifica-se, por meio da análise de regressão, que F. solani apresentou comportamento diferenciadoem relação ao crescimento micelial, frente às diferentes concentrações dos extratos aquosos de alho, canela e cravo-da-índia (Fig. 3).

Houve acentuada redução no diâmetro da colônia de F. solani, quando ele foi transferido para o meio de cultura contendo o extrato aquoso decravo-da-índia. Verifica-se efeito crescente na atividade antifúngica do extrato com o aumento das concentrações, até $8,9 \%$, não sendo constatado crescimento do patógeno a partir desta concentração. Para o extrato aquoso de canela, foi verificada uma relação inversamente proporcional, relatando-se um menor crescimento micelial de F. solani, com a maior concentração do extrato. A tendência de se obter melhores resultados no controle de patógenos nas maiores concentrações também foi observada por Lima et al. (1996).

Em relação ao extrato aquoso de alho, foi observadoinicialmente umacentuado declínio no tamanho da colônia fúngica, com tendência posterior de estabilização, mesmo com a utilização das maiores concentrações. Мотоунма et al. (2003), avaliando o efeito fungitóxico de extrato cítrico, observaram nas menores concentrações (1 e10 ppm) um estímulo no crescimento micelial de F. semitectum. Souza et al. (2007) observaram atividade antifúngica do extrato de alho em todas as concentrações avaliadas, sobre o crescimento de Fusarium proliferatum, porém, assim como constatado neste estudo, a maior eficiência foi verificada na maior concentração analisada.

Assim como relatado para F. solani, pode-se observar uma redução exponencial no crescimento micelial de Phomopsis sp. quando submetido ao extrato aquoso de alho (Fig. 4). Pode ser observado, mesmo com a tendência de estabilização sobre o crescimento do patógeno, que o menor crescimento da colônia fúngica foi encontrado na maior concentração.

Quando se utilizou os extratos de canela e cravoda-índia, verificou-se que o modelo quadrático foi o que melhor se adequou ao crescimento de Phomopsis sp. No entanto, nota-se que o extrato aquoso de cravo-da-índia apresentou-se mais efetivo, não sendo verificado, a partir da concentração de 7\%, crescimento micelial do patógeno. A partir do modelo encontrado para o extrato de canela, pode-se inferir que o menor crescimento micelial do fungo seria obtido com concentração de $19,3 \%$.

Na Tabela 1 são apresentados os resultados do desdobramento com as comparações dos extratos aquosos, dentro de cada concentração utilizada, para o crescimento micelial dos fitopatógenos estudados. Observou-se maior crescimento micelial de C. kikuchii, F. solani e Phomopsis sp., em todas as concentrações testadas, e de Colletotrichum sp. a partir da concentração de $5 \%$, quando submetidos ao tratamento com extrato aquoso de canela, evidenciando o menor potencial desta planta no controle dos fitopatógenos. JHAм et al. (2005), estudando os compostos fungitóxicos do óleo da casca de canela, 
prepararam o extrato de hexano e o óleo obtido de hidrodestilação de casca de canela e verificaram, por meio de cromatografia, que ambos os óleos produziram três frações, sendo constatado que a fração com maior porcentagem de cinamaldeído foi a mais ativa na completa inibição do crescimento de fungos de armazenamento. Nesse sentido, futuros estudos deveriam ser desenvolvidos, com o intuito de se testar diferentes metodologias de obtenção deste extrato, visando aumentar a quantidade de cinamaldeído e, consequentemente, a sua atividade antifúngica.

O extrato aquoso de cravo-da-índia promoveu significativas reduções no crescimento dos fungos. Constatou-se para Colletotrichum sp. e F. solani resultados significativamente superiores, a partir da concentração de $5 \%$, do extrato de cravo quando comparado aos demais extratos aquosos. Em relação ao crescimento de Phomopsis sp., verificou-se superioridade do cravo-da-índia em todas as concentrações utilizadas, com exceção da concentração de $20 \%$, onde ele não diferiu do extrato de alho. No crescimento micelial de C. kikuchii foram observados melhores resultados do extrato de cravo-da-índia apenas na concentração de 5\%. Com exceção ao crescimento de C. kikuchii, a utilização do extrato de alho resultou em atividade antifúngica intermediária sobre o crescimento dos fitopatógenos.

Foiconstatada atividadefungistática coma utilização do extrato aquoso de cravo-da-índia, nas concentrações de 5, 10 e 20\% sobre Phomopsis sp., e apenas nas maiores concentrações sobre Colletotrichum sp. e
F. solani. Em relação à C. kikuchii, esta atividade foi verificada para os extratos de alho e cravo-da-índia, utilizando-se as concentrações de 10 e $20 \%$. Vale salientar que não seria necessária a utilização da maior concentração do extrato de cravo-da-índia para se obter total inibição sobre o crescimento dos fitopatógenos estudados, podendo-seinferirque, mesmo com ouso de menores concentrações, mantêm-se a mesma viabilidade, com a vantagem de redução nos custos.

Oextrato aquoso de alho nas concentrações de10e $20 \%$ apresentaram resultados promissores no controle de Phomopsis sp., pois, além de não permitirem crescimento do patógeno superior a $1 \mathrm{~cm}, 0,64$ e $0,50 \mathrm{~cm}$, respectivamente, foi constatado visualmente nestas concentrações o crescimento de um micélio pouco denso na colônia fúngica em relação ao tratamento controle. Comportamento semelhante foi observado para o extrato de canela, quando utilizado nas mesmas concentrações e para o extrato de cravo-da-índia, nas concentrações de 0,5 e $1 \%$. A colônia fúngica apresentava-se com poucas hifas e aparentemente debilitada em comparação ao tratamento controle. SANCHEZ-MIRT et al. (1993) relataram alterações na membrana citoplasmática dos fungos Cladosporium carrionii e Fonsecaea pedrosoi, após o tratamento com ajoene, um dissulfureto insaturado presente no alho. BIANCHI et al. (1997) afirmam ainda queessas alterações também podem ser provenientes da modificação na atividade enzimática envolvida na membrana e na formação da parede celular, resultando em desenvolvimento anormal do patógeno.

Tabela 1 - Média do crescimento micelial de Colletotrichum sp., Cercospora kikuchii, Fusarium solani e Phomopsis sp. sob influência de extratos aquosos em diferentes concentrações, Dourados, MS, 2008.

\begin{tabular}{|c|c|c|c|c|c|c|}
\hline \multicolumn{7}{|c|}{ Concentrações (\%) } \\
\hline \multirow{2}{*}{ Extrato aquoso } & 0,0 & 0,5 & 1,0 & 5,0 & 10,0 & 20,0 \\
\hline & \multicolumn{6}{|c|}{ Colletotrichum sp. } \\
\hline Alho & $5,81 \mathrm{a}$ & $5,39 \mathrm{ab}$ & $5,00 \mathrm{ab}$ & $3,18 \mathrm{~b}$ & $1,73 \mathrm{~b}$ & $1,32 \mathrm{~b}$ \\
\hline Canela & 5,86 a & $5,47 \mathrm{a}$ & $5,26 a$ & $4,41 \mathrm{a}$ & $3,10 \mathrm{a}$ & $2,74 \mathrm{a}$ \\
\hline Cravo-da-Índia & 5,93 a & $4,90 \mathrm{~b}$ & $4,53 \mathrm{~b}$ & $0,17 \mathrm{c}$ & $0,00 \mathrm{c}$ & $0,00 \mathrm{c}$ \\
\hline \multirow[t]{2}{*}{$\mathrm{CV}(\%)$} & \multicolumn{6}{|c|}{4,36} \\
\hline & \multicolumn{6}{|c|}{ Cercospora kikuchii } \\
\hline Alho & $6,08 \mathrm{a}$ & $5,06 \mathrm{~b}$ & $4,77 \mathrm{~b}$ & $2,11 \mathrm{~b}$ & $0,00 \mathrm{~b}$ & $0,00 \mathrm{~b}$ \\
\hline Canela & $5,96 \mathrm{a}$ & $5,84 \mathrm{a}$ & $5,66 \mathrm{a}$ & $4,98 \mathrm{a}$ & $3,46 \mathrm{a}$ & $1,27 \mathrm{a}$ \\
\hline Cravo-da-Índia & $5,97 \mathrm{a}$ & $5,14 \mathrm{~b}$ & $4,79 \mathrm{~b}$ & $0,13 \mathrm{c}$ & $0,00 \mathrm{~b}$ & $0,00 \mathrm{~b}$ \\
\hline \multirow[t]{2}{*}{$\mathrm{CV}(\%)$} & \multicolumn{6}{|c|}{5,54} \\
\hline & \multicolumn{6}{|c|}{ Fusarium solani } \\
\hline Alho & $5,91 \mathrm{a}$ & $5,16 \mathrm{~b}$ & $4,47 \mathrm{~b}$ & $3,37 \mathrm{~b}$ & $2,01 \mathrm{~b}$ & $1,79 \mathrm{~b}$ \\
\hline Canela & $5,77 \mathrm{a}$ & $5,52 \mathrm{a}$ & $5,46 \mathrm{a}$ & $4,97 \mathrm{a}$ & $4,61 \mathrm{a}$ & $3,77^{a}$ \\
\hline Cravo-da-Índia & $5,79 \mathrm{a}$ & $4,89 \mathrm{~b}$ & $4,63 \mathrm{~b}$ & $1,35 \mathrm{c}$ & $0,00 \mathrm{c}$ & $0,00 c$ \\
\hline \multirow[t]{2}{*}{$\mathrm{CV}(\%)$} & \multicolumn{6}{|c|}{6,65} \\
\hline & \multicolumn{6}{|c|}{ Phomopsis sp. } \\
\hline Alho & $6,88 \mathrm{a}$ & $5,50 \mathrm{~b}$ & $5,16 \mathrm{~b}$ & $1,34 \mathrm{~b}$ & $0,64 \mathrm{~b}$ & $0,50 \mathrm{~b}$ \\
\hline Canela & $7,09 \mathrm{a}$ & $6,18 \mathrm{a}$ & $6,44 \mathrm{a}$ & $4,81 \mathrm{a}$ & $2,84 \mathrm{a}$ & $1,86 \mathrm{a}$ \\
\hline Cravo-da-Índia & $6,73 \mathrm{a}$ & $4,23 \mathrm{c}$ & $3,67 c$ & $0,00 \mathrm{c}$ & $0,00 \mathrm{c}$ & $0,00 \mathrm{~b}$ \\
\hline $\mathrm{CV}(\%)$ & \multicolumn{6}{|c|}{5,31} \\
\hline
\end{tabular}

Médias, seguidas pela mesma letra nas colunas, não diferem entre si pelo teste de Tukey a 5 \% de probabilidade. 
Nas condições em que os bioensaios experimentais foram conduzidos pode-se concluir que o extrato de cravo-da-índia apresenta maior eficácia no controle dos fitopatógenos testados, e proporciona supressão sobre o crescimento de Colletotrichum sp., C. kikuchii, F. solani e de Phomopsis sp. a partir das concentrações de $7,4 \%, 7,5 \%, 8,9 \%$ e $7,0 \%$, respectivamente. Oextrato aquoso dealhocontrola coma mesma eficiência apenas Cercospora kikuchii a partir da concentração de 9,7\%. Para o extrato aquoso de canela constata-se maior atividade antifúngica nas maiores concentrações testadas, sem, no entanto, ocorrer total inibição sobre os fungos fitopatogênicos estudados.

\section{AGRADECIMENTOS}

À CAPES pela concessão da bolsa e à Embrapa Soja pelo fornecimento do isolado fúngico.

\section{REFERÊNCIAS}

BARROS, S.T.; OLIVEIRA, N.T.; MAIA, L.C. Efeito de extrato de bulbo de alho, (Allium satioum L.) sobre o crescimento micelial e germinação de conídios de Alternaria spp. e Curvularia spp. Summa Phytopathologica, v.2, n.2, p.60-62, 1995.

BETTIOL, W. Controle biológico de doenças de plantas. Jaguariúna: Embrapa-CNPDA, 1991.388p.

BIANCHI, A.; ZAMBONELLI, A.; ZECHINI

D'AULERIO, A.; BELLESIA, F. Ultrastructural studies of the effects of Allium sativum on phytopathogenic fungi in vitro. Plant Disease, v.81, n.11, p.1241-1246, 1997.

CUNICO, M.M.; CARVALHO, J.L.S.; ANDRADE, C.A.; MIGUEL, O.G.; MIGUEL, M.D.; AUER, C.G.; GRIGOLETTI JÚNIOR, A.; CÔCCO, L.C.; YAMAMOTO, C.I. Atividade antifúngica de extratos brutos de Ottonia martiana Miq., Piperaceae. Visão Acadêmica, v.7, p.15-24, 2006.

FRANZENER, G.; STANGARLIN, J.R.; SCHWAN-ESTRADA, K.R.F.; CRUZ, M.E.S. Atividade antifúngica e indução de resistência em trigo a Bipolaris sorokiniana por Artemisia camphorata. Acta Scientiarum, v.25, n.2, p.503-507, 2003.

HEINZMANN, B.M. Compostos com enxofre. In: SIMÕES, C.M.O.; SCHENKEL, E.P.; GOSMANN, G.; MELLO, J.C.P.; MENTZ, L.A.; PETROVICK, P.R. (Ed.). Farmacognosia: da planta ao medicamento. Porto Alegre: UFRGS, 2001. p.633-650.

JHAM, G.N.; DHINGRA, O.D.; JARDIM, C.M.; VALENTE, V.M.M. Identification of the major fungitoxic component of cinnamon bark oil. Fitopatologia Brasileira, v.30, n.4, p.404-408, 2005.

LIMA, G.S.A.; LIMA, N.M.F.; LOPEZ, A.M.Q. Efeito de extratos aquosos de bulbos de alho (Allium sativum) sobre a germinação e o crescimento micelial de Botryodiplodia theobromae Pat. in vitro. Ciência Agrícola, v.4, p.1-9, 1996.

LYON, G.D.; REGLINSKI, T.; NEWTON, A.C. Novel disease control compounds: the potential to "immunize" plants against infection. Plant Pathology, v.44, p.407-427, 1995.

MOTOYAMA, M.M.; SCHWAN-ESTRADA, K.R.F.; STANGARLIN, J.R.; FIORI-TUTIDA, A.C.G.; SCAPIM, C.A. Indução de fitoalexinas em soja e em sorgo e efeito fungitóxico de extratos cítricos sobre Colletotrichum lagenarium e Fusarium semitectum. Acta Scientiarum, v.25, n.2, p.491-496, 2003.

RANASINGHE, L.; JAYAWARDENA, B.; ABEYWICKRAMA, K. Fungicidal activity of essential oils of Cinnamomum zeilanicum (L.) and Syzygium aromaticum (L.) Merr et LM. Perry against crown rot anthracnose pathogens isolated from banana. Letters in Applied Microbiology, v.35, p.208-211, 2002.

RIBEIRO, L.F.; BEDENDO, I.P. Efeito inibitório de extratos vegetais sobre Colletotrichum gloesporioides Agente causal da podridão de frutos de mamoeiro. Scientia Agrícola, v.56, n.4, p.1267-1271, 1999.

RODRIGUES, E.A.; SCHWAN-ESTRADA, K.R.F.; STANGARLIN, J.R.; SCAPIM, C.A.; FIORI-TUTIDA, A. C.G. Potencial da planta medicinal Ocimum gratissimum no controle de Bipolaris sorokiniana em sementes de trigo. Acta Scientiarum, v.28, n.2, p.213-220, 2006.

ROZWALKA, L.C.; LIMA, M.L.R.Z.C.; MIO, L.L.M.; NAKASHIMA, T. Extratos, decoctos e óleos essenciais de plantas medicinais e aromáticas na inibição de Glomerella cingulata e Colletotrichum gloeosporioides de frutos de goiaba. Ciência Rural, v.38, n.2, p.301-307, 2008.

SANCHEZ-MIRT, A.; GIL, F.; APIZ-CASTRO, R. Efecto inhibithorio y alteraciones ultraestructurales producidas por ajoeno sobre el crecimento in vitro de los hongos dematiaceos: Cladosporium carrionii y Fonsecaea pedrosoi. Revista Iberoamericana de Micologia, v.10, n.3, p.74-78, 1993.

SOUZA, A.E.F.; ARAÚJO, E.; NASCIMENTO, L.C. Atividade antifúngica de extratos de alho e capim-santo sobre o desenvolvimento de Fusarium proliferatum isolado de grãos de milho. Fitopatologia Brasileira, v.32, n.6, p.465-471, 2007.

STANGARLIN, J.R.; SCHWAN-ESTRADA, K.R.F.; CRUZ, M.E.S.; NOZAKI, M.H. Plantas medicinais e controle alternativo de fitopatógenos. Biotecnologia Ciência \& Desenvolvimento, n.11, p.16-21, 1999.

TALAMINI, V.; STADNIK, M.J. Extratos vegetais e de algas no controle de doenças de plantas. In: STADNIK, M.J.; TALAMINI, V. (Ed.). Manejo ecológico de doenças de plantas. Florianópolis: CCA/UFSC, 2004. p.45-62.

Recebido em $1 / 3 / 10$

Aceito em 2/1/11 